\title{
Methodological challenges and pragmatic design in randomised controlled trials comparing surgery and rehabilitation
}

\author{
Vandana Ayyar Gupta ${ }^{*}$, Antony Palmer ${ }^{1}$, Ines Rombach', Susan Dutton', Cushla Cooper ${ }^{1}$, Karen Barker $^{2}$, \\ David Beard ${ }^{1}$, Sion Glyn-Jones ${ }^{1}$
}

From 3rd International Clinical Trials Methodology Conference

Glasgow, UK. 16-17 November 2015

Randomised controlled trials (RCTs) evaluating surgery versus rehabilitation pose particular methodological and practical challenges. In addition to the differences in the interventions, factors associated with the differences in care pathways and fluctuating symptoms impact the feasibility of effectively running a trial in a hospital setting.

FAIT is such a RCT comparing arthroscopy versus physiotherapy rehabilitation for the management of femoroacetabular impingement in young adults. The trial is ongoing and aims to recruit a maximum of 214 participants by July 2016. Currently, 130 participants (at least $60 \%$ of maximum target) have been recruited. There are five participating centres showing variability in the recruitment rates. Feasibility work conducted prior to the trial concluded that $90 \%$ of eligible patients are willing to participate. However, the proportion of eligible patients optingin is lower than that suggested by the feasibility study. The main factor identified as affecting recruitment and conduct of the trial is patient preference for surgery. Additionally, factors such as differences in waiting times, surgeon equipoise and fluctuating symptoms of the condition present significant constraints on planning the design and analysis for the trial. Alternate post-intervention design, treatment crossover, effective communication of treatment equipoise and careful site selection were considered to address these challenges. We highlight some unique challenges which influence conducting trials that specifically compare surgical intervention with rehabilitation. We aim to describe our experience and the decision making process involved in the planning and conduct of a pragmatic

${ }^{1}$ Nuffield Department of Orthopaedics, Rheumatology and Musculoskeletal Sciences, University of Oxford, Oxford, UK

Full list of author information is available at the end of the article design for such a comparison in the context of the FAIT trial.

\section{Authors' details}

${ }^{1}$ Nuffield Department of Orthopaedics, Rheumatology and Musculoskeletal Sciences, University of Oxford, Oxford, UK. ${ }^{2}$ Oxford University Hospitals NHS Trust, Oxford, UK.

Published: 16 November 2015

doi:10.1186/1745-6215-16-S2-P172

Cite this article as: Gupta et al:: Methodological challenges and pragmatic design in randomised controlled trials comparing surgery and rehabilitation. Trials 2015 16(Suppl 2):P172.
Submit your next manuscript to BioMed Central and take full advantage of:

- Convenient online submission

- Thorough peer review

- No space constraints or color figure charges

- Immediate publication on acceptance

- Inclusion in PubMed, CAS, Scopus and Google Scholar

- Research which is freely available for redistribution
() Biomed Central 